Proceedings

\title{
The relationship between urban environment, sociodemo- graphic variable and the use of BRT public transport in Quito
}

\author{
Alba Cristina Núñez Basantes ${ }^{1}$
}

${ }_{1}^{1}$ Universidad Politécnica de Valencia; anuez@doctor.upv.es

2 Universidad Central del Ecuador; anunez@uce.edu.ec

Citation: Núñez,A., 2022, The relationship between urban environment, sociodemographic variable and the use of BRT public transport in Quito. SUPTM 2022 conference proceedings sciforum-054221.

https://doi.org/10.31428/10317/10582

Publisher's Note: UPCT and Sciforum stays neutral with regard to jurisdictional claims in published maps and institutional affiliations.

Copyright: (c) 2022 by the authors. Submitted for possible open access publication under the terms and conditions of the Creative Commons Attribution (CC BY) license (https://creativecommons.org/license s/by/4.0/).

\begin{abstract}
:
This paper examines the relationship between the number of passengers who access walking to the 42 stations of the Bus Rapid Transit (BRT) system in Quito, Ecuador and urban variables. For this purpose, a Direct Ridership Model (DRM) is built, relying on Geographic Information Systems (to define the service area and calculate its urban characteristics within a pedestrian distance threshold of 600 meters) and a multiple linear regression model (to explain the number of entries per station as a function of the urban environment). The results reveal that the number of boarding maintains correlation with the density of the network, land use, shape index, sidewalk width, distance to the business center, while, population density is not significant, even though is necessary to explain the model.
\end{abstract}

Keywords: Direct Ridership Model, urban environment, BRT

\section{Background and current status}

The increasing relevance of the relations between surrounding areas and central areas and the rising vehicular traffic lead to transformations in the current city model, changes that, in most cases, have to be adjusted to an already established context. For this reason, it is important to consider those urban approaches that start by affirming the circular nature of the relationships between spatial organization, forms of transport and mobility.

Regarding this, numerous studies analyze the transport demand according to the urban environment, whether it is or it is not part of a type of urban morphology oriented towards public transport, and their findings show that urban planning variables influence public transport. Thus, density, diversity, design and accessibility maintain significance in the calculation of demand for both, rail transport (Cardozo et al., 2010; Chan \& Miranda-Moreno, 2013; Choi et al., 2012; Loo et al, 2010; Sohn \& Shim, 2010) as well as for BRT systems (Cervero \& Dai, 2014; Estupiñán \& Rodríguez, 2008; Rodriguez \& VergelTovar, 2017), however, the significant result depends on some factors, including the environment and the type of transport system.

Certainly, due to these differences and certain existing gaps, in this article it is proposed as an objective to analyze the influence of the urban environment on BRT demand. For this purpose, 42 BRT stations in Quito, Ecuador, in the situation of 2016 are considered and with the urban variables taken from the immediate surroundings of these, it is tried to explain the number of passengers entering on foot to each of the stations (i.e., users who maintain close proximity to the environment) from the calculation of a Direct Ridership Model (DRM), which relies on the capabilities of Geographic Information Systems (GIS) and statistical analysis techniques (multiple regression). 
From this approach, the interest of the article is twofold. On the one side, it emphasizes the relationships between urban variables and the BRT use, trying to explain the higher or lower number of people entering the stations, which is essential in a system that registers a high number of pedestrian entries, as is the case of the BRT in Quito. On the other side, this way of calculating demand is a necessary tool for both transport planners and urban planners, since, for the first group, it allows them to predict demand quickly and reliably, which facilitates network management, and for the second one, with this methodology, they can propose more sustainable urban models, considering the location of land uses near the transport systems.

In addition to this introduction, the article is structured in four more sections, in order to fulfill the objective set. Thus, the second section is the state of the question, the third, the steps applied in the analysis of the demand of Quito's BRT system. Lastly, the fourth section presents the results obtained and the conclusions.

\section{Methodology}

With the aim of deepening the findings found in previous studies on the association between population density, land use mix, urban design, accessibility and BRT demand, the urban environment immediately surrounding the stations of two corridors of Quito's BRT system (MetrobusQuito) is examined. They were selected because they meet two characteristics, first, they are exclusive lanes (reserved for BRT use only) and, second, the circuits have been in operation for more than 10 years, according to Wright \& Hook (2010), both of which denote consolidation in the urban environment immediately surrounding the stations, which allows their analysis.

After defining the object and selecting the case study, the research question is: what are the relationships between the attributes of the urban environment and the number of passengers in the Quito BRT system? To answer this question, the Direct Estimation Method (DRM) is proposed with the support of GIS and statistical analysis (Multiple Regression). The DRM consists of three stages: 1 . Delimitation of service areas; 2 . Calculation of urban and socioeconomic variables; 3. Multiple Regression Model (Demand Model)

\subsection{Application of the MRD: 42 BRT stations in Quito}

This study, the Trolebus and Ecovia corridors are considered for having 27.5 kilometers of exclusive lanes and being in operation for more than 10 years.

\subsection{Temporal and spatial delimitation}

Once the service areas have been calculated, the 4,417 segments within them are coded with the initials of the street names and a cardinal numeral. This process facilitates the collection of data from primary sources through the PEDS cards and the organization of data obtained from secondary sources. With the data collected, the maps are elaborated, which are superimposed to calculate the external variables.

Thus, by placing the map of the number of residents at block scale on the service areas, the population density is obtained, but the total number of inhabitants of the blocks that are fractioned because they are located on the edge is not considered, so, to distribute them according to their corresponding area, the area proportion method is used ( $\mathrm{O}$ 'Neill et al., 1992). A similar process is used to obtain some of the urban variables, for example, by combining the road network with the service area, its density is obtained (Cardozo et al., 2010). The mix index uses the land use typologies (i.e., health, office, administration, education, hotel, financial, security, culture and welfare) of each station in relation to those existing in the total intervention area (Estupiñán \& Rodríguez, 2008; Ewing \& Cervero, 2010).

Other variables are calculated with the support of GIS, such as accessibility to the destination or business center (CBD) measured by the distance between the station and the 
CBD (Cardozo et al., 2010; Ewing \& Cervero, 2010; Vergel-Tovar \& Rodriguez, 2014); the shape index obtained from the ratio between the service area, with distance across the network, and the buffer area, with Euclidean distance (Haggett, 1976); and the number of bus lines within the service area. Some urban variables are also calculated with the GIS, such as the number of segments with pedestrian facilities, i.e., those with benches, trash cans and/or public lighting, the traffic control index that is constructed with the segments that have crosswalks, pedestrian traffic lights and ramps (Estupiñán \& Rodríguez, 2008), and the intensity of land use that corresponds to the total number of uses of each typology within the service area. Finally, the geometric mean is used to calculate the daily income.

\subsection{The multiple regression model (MRD)}

No.UsuariosBRTi $=\beta$ o $600+\beta 1 \quad$ Dist i $600+\beta 2$ LineaBuses $i 600+\beta 3$

Po_Hec_Km2 i 600

$+\beta 4$ NoUsos i $600+\beta 5$ IndForma i $600+\beta 6$ DenRed i $600+\beta 7$ acera i $600+E$

Where

NoUsuarios BRT $=$ geometric mean of the number of 2015 entries; $\mathrm{B}$ o $=$ intercepto; $\beta$ 1 = estimation coefficient; Dist $i=$ distance from the stop to the business center $i$; $\beta 2=$ estimation coefficient; LineaBuses $=$ number of buses $i ; \beta 3$ = estimation coefficient; Po_Hec_Km2 $i=$ Population density per Km2 $i$; $\beta 4$ = estimation coefficient; NoUsos $i=$ Number of land uses $i ; \beta 5=$ estimation coefficient; IndForma $i=$ index of the shape $i ; \beta 6=$ estimation coefficient; DenRed $i=$ Density of the network $i$; $\beta 7$ = estimation coefficient; acera $i=$ Number of segments that have less than one meter of sidewalk width $i$

\section{Description and analysis of results}

Table 1 shows the description of the results of the multiple linear regression model. The maximum explanatory power is reached when including the variables distance to the business center, the density of the network, the number of land uses, the shape index, the number of sidewalk segments measuring less than one meter wide, the conventional bus lines (as a sign of complementarity between public transportation forms) and the density of the population, although these two last variables only participate in the model because they give significance to the other variables. With the above variables, the model fit achieves a coefficient of determination $\mathrm{R} 2$ of 0.67 , which confirms that the four urban domains density, diversity, design and accessibility to the destination have an influence on BRT transport in Quito.

Looking at the coefficients, most of them are as expected. Thus, for example, the density of the network, the number of land uses, and the shape index are variables that have a positive sign (i.e., if any of them increases, the number of BRT users would increase). On the other side, the distance to the business center and the number of sidewalk segments with a width of less than one meter are inversely proportional, which is also in line with the prediction, because if the distance between the destination (business center) and the stop increases, or if pedestrian accessibility decreases (due to sidewalks measuring less than one meter), users would certainly be less motivated to use the transportation system. What could be considered unexpected in Anglo-Saxon studies carried out in spaces with TOD characteristics is the behavior of the population density variable; its coefficient is negative and, moreover, it has no explanatory power. However, in the analysis of the Latin American environment, where the characteristics do not precisely respond to a transport-oriented development, this is possible, i.e., this result revalidates the findings on the behavior of the population in this type of urban model, and in this particular case, it also includes conventional bus routes as non-significant variables. 


\section{Conclusion}

This research deepens and broadens previous knowledge on the three factors: density, diversity, design and accessibility to the destination. Thus, network density, land use and distance from the station to the business center are significant which confirms the findings of works on rail demand (Cardozo et al., 2010; Ewing \& Cervero, 2010) and, to the few existing ones, BRT (Cervero et al., 2010; Cervero \& Dai, 2014; Estupiñán \& Rodríguez, 2008; Vergel-Tovar \& Rodriguez, 2018). The model, in addition, involves understudied variables such as the shape index and the number of segments that have a sidewalk width less than one meter. Finally, in light of the results found, the population density variable is necessary, but not significant enough to predict the demand for Quito's BRT system, perhaps this responds to the urban model that rules in this city and in many others in Latin America.

In terms of planning, the study suggests considering an urban model with several centralities that decreases the distance between the places of origin and destination of travel, with a public transportation system that integrates human settlements, with public spaces oriented for pedestrians. And, in the area of transportation, it is proposed to involve these variables in the analysis of demand, especially the distance from the station to the nearest centrality, otherwise, the number of passengers in the transportation system tends to be overestimated or underestimated.

\section{References}

Cardozo, O. D., Gutiérrez, J., \& Palomares, G. (2010). Influencia de la morfología urbana en la demanda de transporte público: Análisis mediante SIG y modelos de regresión múltiple. Geofocus, 10(4), 21.

Cervero, R., \& Dai, D. (2014). BRT TOD: Leveraging transit oriented development with bus rapid transit investments. Transport Policy, 36, 127-138. doi: 10.1016/j.tranpol.2014.08.001

Cervero, R., Murakami, J., \& Miller, M. (2010). Direct ridership model of bus rapid transit in Los Angeles County, California. Transportation Research Record, 1, 1-7.

Chan, S., \& Miranda-Moreno, L. (2013). A station-level ridership model for the metro network in Montreal, Quebec. Canadian Journal of Civil Engineering, 40(3), 254-262. doi: 10.1139/cjce-2011-0432

Choi, J., Lee, Y. J., Kim, T., \& Sohn, K. (2012). An analysis of Metro ridership at the station-to-station level in Seoul. Transportation, 39(3), 705-722. doi: 10.1007/s11116-011-9368-3

Estupiñán, N., \& Rodríguez, D. A. (2008). The relationship between urban form and station boardings for Bogotá's BRT. Transportation Research Part A: Policy and Practice, 42(2), 296-306. doi: 10.1016/j.tra.2007.10.006

Ewing, R., \& Cervero, R. (2010). Travel and the Built Environment: A Meta-Analysis. Journal of the American Planning Association, 76(3), 265-294. doi: 10.1080/01944361003766766

Haggett, P. (1976). Análisis locacional en la geografía humana. Barcelona.

Kline, P. (2014). An Easy Guide to Factor Analysis. Routledge.

Loo, B. P. Y., Chen, C., \& Chan, E. T. H. (2010). Rail-based transit-oriented development: Lessons from New York City and Hong Kong. Landscape and Urban Planning, 97(3), 202-212. doi: 10.1016/j.landurbplan.2010.06.002

O'Neill, W., Ramsey, D., \& Chou, J. (1992). Analysis of transit service areas using geographic information systems. Transportation Research Record, 1364, 131-138.

Rodriguez, D. A., \& Vergel-Tovar, C. E. (2017). Urban development around bus rapid transit stops in seven cities in Latin-America. Journal of Urbanism: International Research on Placemaking and Urban Sustainability, 11(2), 175-201. doi: 10.1080/17549175.2017.1372507

Sohn, K., \& Shim, H. (2010). Factors generating boardings at Metro stations in the Seoul metropolitan area. Cities, 27(5), 358-368. doi: 10.1016/j.cities.2010.05.001

Vergel-Tovar, E., \& Rodriguez, D. (2014). Examining the relationship between BRT ridership and the built environment in Latin America. Recuperado de https://www.slideshare.net/EMBARQNetwork/moving-beyond-streets-for-cars-madeline-brozen?next_slideshow $=1$

Vergel-Tovar, E., \& Rodriguez, D. A. (2018). The ridership performance of the built environment for BRT systems: Evidence from Latin America. Journal of Transport Geography, 73, 172-184. doi: 10.1016/j.jtrangeo.2018.06.018 